\title{
The effects of ITI interpolated stimuli and CS intensity on classical conditioning of the nictitating membrane response of the rabbit
}

W. RONALD SALAFIA, Fairfield University, Fairfield, Conn. 06430 and JAMES D. PAPSDORF, University of Michigan, Ann Arbor, Mich. 48104

The effects of white noise bursts of 5 sec duration, interpolated $30 \mathrm{sec}$ into a $1 \mathrm{~min} I T I$, were compared on the conditioning rates of Ss trained under high and low CS intensities. The interpolated stimulus produced a significant decrement in conditioning at the high but not at the low intensity value. It is suggested that higher CS intensities may shorten the time available for ITI consolidation.

White noise bursts in the intertrial interval (ITI) have been found to retard the rate of conditioning of the nictitating membrane response in a manner suggesting the presence of an ITI consolidation process (Papsdorf \& Kettlewell, 1968), and Snyder \& Papsdorf (1968) have shown that this vulnerability to interpolated stimuli varies with the interstimulus interval (ISI). Thus, a white noise burst occurring $30 \mathrm{sec}$ into the ITI following a $350 \mathrm{msec}$ ISI had relatively little effect on acquisition rate, while there was a marked decrement when such bursts followed a $750 \mathrm{msec}$ ISI. The purpose of the present investigation was to determine whether the effects of ITI interpolated stimuli are influenced by another major classical conditioning variable, viz CS intensity.

Subjects

The Ss were 32 albino rabbits, $80-100$ days old, obtained through the facilities of the Animal Care Unit of The University of Michigan, and maintained on ad lib food and water.

Procedure

Forty-eight hours prior to the first experimental session, Ss were prepared by having a nylon loop tied into the nictitating membrane of the right eye. On the following day each $S$ was placed in a Plexiglas restraining box for a $15 \mathrm{~min}$ habituation period. During this period, as in the experimental sessions, tailor hooks, which served the dual purpose of retracting the eyelids and delivering the shock US, were fastened by an adjustable Velcro strap to the inferior and superior lids of the right eye. Movements of the nictitating membrane were monitored by a small photoelectric transducer, mounted on S's head by means of a muzzle-like assembly, and mechanically coupled to the loop in the membrane. Signals from the transducer were amplified and graphically recorded by a Beckman Type $R$ Dynograph. The above apparatus and procedure have been described in detail by Gomezano (1966).

Conditioning sessions began on the day following habituation and continued, one per day for seven days or until a criterion of two successive sessions with no less than $90 \%$ CRs was reached. Each conditioning session consisted of preparing the $S s$ as described above, and then presenting 15 CS-US pairings at a fixed ITI of $60 \mathrm{sec}$ and an ISI of $350 \mathrm{msec}$. For all Ss, the CS was a $1000 \mathrm{cps}$ tone and the US was a $3 \mathrm{~mA}$ $60 \mathrm{cps}$ shock delivered to the eyelids and overlapping the last $100 \mathrm{msec}$ of CS presentation. The $32 \mathrm{Ss}$ were randomly assigned to four groups $(\mathrm{N}=8)$ in a 2 by 2 design with $\mathrm{CS}$ intensity levels of 83 and $93 \mathrm{~dB}$ orthogonal to the presence or absence of a $5 \mathrm{sec}$ burst of $85 \mathrm{~dB}$ white noise occurring $30 \mathrm{sec}$ into the ITI. A CR was defined as a pen deflection of at least 1 $\mathrm{mm}$, occurring at least $50 \mathrm{msec}$ after CS onset and up to the time of US onset. (One $S$ in the low CS intensity control group was withdrawn prior to completion of the experiment for reasons of heaith, leaving a final $\mathrm{N}$ of seven in that group.) Results

The mean percentage of CRs for the four groups on each of the seven conditioning sessions is presented in Fig. 1 . In the construction of this graph and in the statistical analysis, the extrapolated performance scures for a $S$ attaining criterion prior to the seventh conditioning session were equated with his performance on his second criterion session. Examination of the figure indicates that ITI white noise bursts had only a slight decremental effect on conditioning rates at the low CS intensity value, while producing a marked depression in the acquisition function of the high CS intensity group. Mann-Whitney $U$ tests between interpolated and control groups revealed that the small difference in conditioning over the seven sessions between the low CS intensity groups was not statistically significant $(p=.198)$ while this difference between the high CS intensity groups was highly significant $(p=.014)$. Noteworthy was the fact that the low CS control group demonstrated somewhat superior conditioning over the high CS intensity control group, although the difference was small and nonsignificant $(p=.347)$.

Discussion

In their elaboration of the ITI consolidation hypothesis, the basic notion of which is that US presentation on Trial $\mathbf{N}+1$ disrupts non-consolidated associative traces activated by CS-US presentation on Trial N, Papsdorf \& Kettlewell (1968) postulated the existence of a short post-US consolidationsuspension period since white noise bursts occurring $10 \mathrm{sec}$ after US offset had less of a depressive effect on conditioning rates than such stimuli occurring 30 sec after shock termination. It was suggested that persisting CNS desynchronization, attributable to the arousal-provoking effects of the shock US, was so intense for a period after US termination that ITI consolidation was suspended. Interpolation of white noise bursts during this "hold" period were of little consequence as the effects they normally induce, cortical desynchronization, were still present as an after-reaction to shock. The results of the present investigation, i.e., greater ITI vulnerability to white noise bursts in the high CS intensity group and slightly faster conditioning in the low CS intensity control group with respect to the high CS control group, can

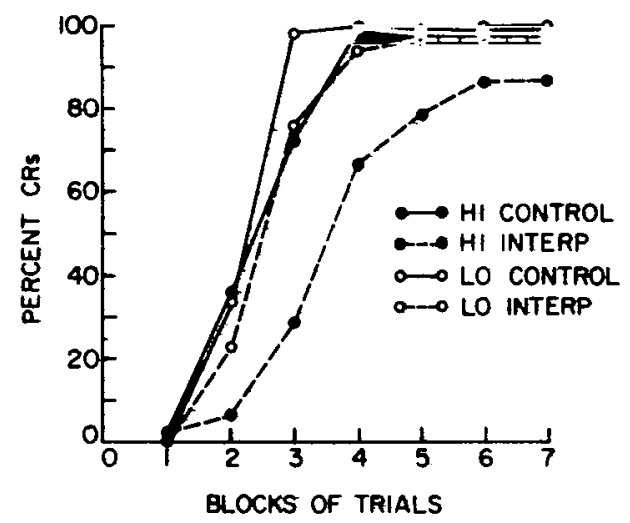

Fig. 1. Percentage CRs on each of the seven conditioning sessions. 
be adequately handled by the ITI consolidation hypothesis if it is assumed that the duration of the "hold" period varies directly with CS intensity. Thus, with respect to the control groups and the slight superiority of the low CS intensity Ss, whatever positive contribution increases in CS intensity make to the conditioning process, they were more than offset in the present investigation by the shorter ITI time available for consolidation. The longer "hold" period of the high CS intensity Ss not only reduced the time available for ITI consolidation but indirectly increased ITI vulnerability to white noise bursts by delaying the onset of consolidation and thus insuring less completion of consolidation by the onset time of white noise presentation. Since the arousal effects of the shock US are presumed to underlie this "hold" period, it is not inconceivable that the intensity parameter of the C.S, which determines its arousal value, would also play some role in determining "hold" period duration. This hypothesis can be tested by manipulations of CS intensity and ITI. With massed trials $(\mathrm{ITI} \cong 20 \mathrm{sec})$ higher $\mathrm{CS}$ intensities should produce a decrement in conditioning relative to low CS values and as the ITI is increased, this ordering should be reversed. A somewhat similar interaction between ITI and US intensity has already been observed in humans (Frokasy et al, 1958) and rabbits (Papsdorf et al, 1964) and is in agreement with the above reasoning if it assumed that the duration of the "hold" period is also determined by US intensity.

As indicated earlier, Snyder \& Papsdorf (1968) observed that interpolations of white noise bursts $30 \mathrm{sec}$ into a $1 \mathrm{~min}$ ITI had little effect on conditioning rates of Ss trained at a $350 \mathrm{msec}$ ISI, while producing a marked decrement in the conditioning rates of Ss trained at a $750 \mathrm{msec}$ ISI. Two hypotheses were advocated to account for the interaction: (1) faster ITI consolidation at the shorter ISI due to fewer functional synapses between the CS and US dominant foci; (2) greater associative representation or trace strength at the shorter ISI (Hull, 1943; p. 168) which served to increase ITI consolidation rates, possible by some mass-action biochemical process (John, 1967; p. 62), or offset the reactive inhibition generated by occasional responding to the white noise bursts. The present investigation was conceived in part as a test of these hypotheses in that if trace strength is the major determinant of this interaction. increasing CS intensity, which presumably also augments the magnitude of associative representation (Hull, 1943; p. 169), should produce an interaction parallel to the ISI function of Snyder \& Papsdorf (1968). As the interaction of the present investigation runs directly opposite to that predicted by the. associative strength hypothesis, the hypothesis of ISI determination of ITI consolidation rates due to variable synaptic separations would appear to be more tenable in accounting for the Snyder \& Papsdorf (1968) results.

However, complete rejection of the associative strength hypothesis in accounting for the Snyder \& Papsdorf (1968) interaction is as yet unwarranted, since any positive contribution increases in CS intensity made to associative development have been offset by delayed onset of ITI consolidation due to prolongation of the "hold" period. A more adequate assessment of the alternative hypotheses awaits determination of the offset times of the "hold" periods following low and high CS intensities with parametric comparisons of the effects of white noise bursts in the ITI at various intervals measured from these offset points.

\section{REFERENCES}

GORMEZANO, I. Classical conditioning. In J. B. Sidowski (Ed.), Experimental methods and instrumentation in psychology. New York: McGraw-Hill, 1966.

HULL, C. L. Principles of behavior. New York: Appleton-CenturyCrofts, 1943.

JOHN, E. R. Mechanisms of memory. New York: Academic Press, 1967. PAPSDORF, J. D., \& KETTLEWELL, N. M. The effects of different interpolated ITI stimulus-conditioned stimulus intervals on the acquisition of the classically conditioned nictitating membrane response of the rabbit. Psychonomic Science, 1968, 10, 171-172.

PAPSDORF, J. D., GORMEZANO, I., \& PROKASY, W. F. Intertrial interval and UCS intensity effects on the acquisition and extinction of the classically conditioned nictitating membrane response of the rabbit. Paper read at Midwestern Psychological Association, Chicago, Illinois, 1964.

PROKASY, W. F., GRANT, D. A., \& MYERS, N. A. Eyelid conditioning as a function of unconditioned stimulus intensity and intertrial interval. Journal of Experimental Psychology, 1958, 55, 242-246.

SYNDER, R. E., \& PAPSDORF, J. D. The interaction of ITI interpolated stimuli and ISI on classical conditioning of the nictitating membrane response of the rabbit. Psychonomic Science, 1968, in press. NOTE

1. This study was supported in part by grants from (1) the National Science Foundation, Research College Teaching Program to W. Ronald Salafia; (2) the National Institutes of Mental Health to James D. Papsdorf, NIH MH 12504-02.

\section{ERRATUM}

DAVENPORT. D. G., \& MUELLER, J. H. Resistance to extinction as a function of nonresponse incentive shift. Psychonomic Science, $1968,10(7), 243-244-$ On page 244 , 2nd column, the 11 th and 12 th lines should read "ing with small rewards produces greater $\mathrm{RE}$, whereas with large rewards it decreases RE." 